\title{
Percepções de Competência: Um Estudo com Crianças e Adolescentes do Ensino Fundamental
}

\author{
Gustavo de Almeida* \\ Nadia Cristina Valentini** \\ Adriana Berleze ${ }^{* * *}$
}

Resumo: Este estudo teve o objetivo de investigar como as crianças expressam suas percepções de competência nos diferentes domínios do comportamento humano. Foi utilizada a Escala de Percepção de Competência para Crianças com 96 crianças do ensino fundamental público. Os resultados sugerem que: a) crianças mais velhas apresentam níveis menores de percepção de competência; b) as percepções de competência de meninos e meninas nos diferentes domínios foram semeIhantes; c) a percepção de competência escolar é mais baixa para as crianças mais velhas e repetentes; e, d) a menor competência escolar percebida, parece não afetar os níveis de competência nos demais domínios.

Palavras-chave: Percepção. Educação baseada em competências. Criança.

\section{INTRODUÇÃO}

Ao longo do processo de desenvolvimento, o indivíduo busca relacionar-se de forma eficiente com o ambiente, tornando-se mais competente. A qualidade dessas interações conduzirá a criança à conquista da autonomia e a autoconfiança em suas habilidades e, consequentemente, a perceber-se competente (WHITE, 1959; HARTER, 1978, 1985, 1992). A competência percebida, entendida como o julgamento expresso pelo indivíduo relativo a uma capacidade realizada (VALENTINI, 2002a), pode ser expressa pela criança na

\footnotetext{
* Graduado Educação Física. Universidade Federal do Rio Grande do Sul. Curso de Educação Física, Porto Alegre, RS, Brasil. E-mail: gugaesef@gmail.com

** PhD. Comportamento Motor. Professor do Curso de Educação Física da Universidade Federal do Rio Grande do Sul. Porto Alegre, RS, Brasil. E-mail: nadiacv@esef.ufrgs.br

*** Doutoranda Ciências do Movimento Humano da Escola de Educação Física da Universidade Federal do Rio Grande do Sul. Porto Alegre, RS, Brasil. E-mail: adrianaberleze@yahoo.com.br
} 
infância em domínios específicos do comportamento humano (cognitivo, social ou motor); sendo, portanto, multidimensional. Entretanto, as mesmas podem mudar em decorrência das experiências dependendo de suas conquistas. Essa abordagem multidimensional permite verificar em qual domínio a criança investiu, ou está investindo, maior energia e esforço, para tornar-se competente.

Quanto maior o nível de realizações ou conquistas, mais provável é que o indivíduo perceba-se competente no específico domínio em que sua ação foi eficiente no ambiente (HARTER, 1978, 1984, 1992, 1999) conduzindo o indivíduo a sentir prazer em descobrir o que consegue fazer bem (GALLAHUE, 2001). Percepções positivas de competência são influenciadas pelas características do indivíduo (idade, gênero, motivação) em interação com os valores de agentes socializadores (pais, pares, professores); e de como os agentes socializadores respondem aos esforços das crianças nos contextos específicos de aprendizagem em que a mesma está socialmente inserida (HARTER, 1978). Esses fatores são decisivos no desenvolvimento da própria competência; na confiança na própria habilidade de efetivamente interagir no ambiente; fortalecendo, portanto, a auto estima e o autoconceito (GALLAHUE, 2001; VALENTINI, 2007; VIEIRA et al., 1997).

\section{As CARACTERISTICAS DO INDIVIDUO E AS PERCEPÇÕES DE COMPETÊNCIA}

O processo de socialização da criança se diferencia considerando-se as características pertinentes as diferentes faixas etárias, ao gênero e a própria motivação intrínseca da criança ao realizar diferentes tarefas. Quanto à idade, vários estudos sugerem crianças mais jovens superestimando suas competências em decorrência da pouca experiência para realizar julgamentos autônomos, sendo que o julgamento relativo às capacidades e aptidões é baseado inteiramente no feedback social, em geral, proveniente de pais e professores. Crianças mais velhas (acima de 10 anos) passam a considerar suas expectativas próprias de padrões sociais, bem como o feedback social fornecido por pessoas importantes, como os pares, na elaboração

Movimento, Porto Alegre, v. 15, n. 01, p. 71-97, janeiro/março de 2009. 
de seu julgamento. Desse modo, nas crianças mais velhas, os sentimentos de competência passam a ser autodeterminados e mais realistas quanto as suas próprias competências; ou seja, crianças mais velhas tendem a não mais superestimem suas competências (GALLAHUE, 2001; GOODWAY; RUDISILL, 1996; HARTER, 1978; HARTER; CONNEL, 1984; MAÏANO et al., 2004; PIEK et al., 2006; RUDISILL et al., 1993; VIEIRA et al., 1997; ULRICH, 1987; WHITE, 1959). Entretanto, é importante destacar que alguns estudos evidenciam que não necessariamente crianças mais velhas são precisas sobre suas competências e que as mesmas podem evidenciar percepções superestimadas similares as observadas na infância. Esta percepção não realista é decorrente da falta de parâmetros para julgar a própria competência; e, pode ser prevalente quando o contexto não contribui de forma a auxiliar as mesmas a construir critérios internos de julgamento de suas habilidades e capacidades (RUDISILL et al., 1993; VALENTIN, 2007, 2002b).

Crianças e adolescentes que superestimam suas capacidades tendem a julgar todas as tarefas como fáceis. Julgar uma tarefa como fácil engajar-se na tarefa e ter essa experiência fracassada resulta em baixas percepções de competência. Em contrapartida, quando a criança e o adolescente subestimam sua competência atual, ela pode ter baixas expectativas para competências futuras, influenciando negativamente os resultados de sua performance (RUDISILL et al., 1993; VALENTINI, 2007, 2002b). As experiências negativas resultam em uma percepção de competência imprecisa e essa falta de precisão pode resultar em expectativas irreais frente a uma tarefa. Portanto, as percepções de competência, para um determinado domínio, podem ser consideradas como o resultado de uma história de conquistas e fracassos. A criança que se percebe como desvalorizada devido a constantes fracassos utiliza a estratégia de afastar-se deliberadamente da atividade, protegendo sua habilidade (HARTER, 1978). Além disso, quando as crianças percebem que possuem dificuldades nas tarefas é possível que elas evitem essa experiência, perdendo oportunidades vitais de desenvolvimento de novas habilidades (PIEK et al., 2006). Ressalva-se, entretanto, que o envolvimento da criança no processo de aprendizagem é dependente também do

Movimento, Porto Alegre, v. 15, n. 01, p. 71-97, janeiro/março de 2009. 
valor atribuído pela criança à atividade. Repercussões negativas no autoconceito parecem só ocorrer quando a criança valoriza a tarefa e percebe-se, nesta tarefa, pouco competente. Quando emoções positivas de conquista estão relacionadas com a tarefa, a criança demonstra engajamento e continuidade na participação (CARROL et al., 2001; VALENTINI, 2007).

Diferentes processos de socialização podem influenciar as percepções de meninos e meninas, refletindo a cultura em que a criança está inserida. Desde a infância, as crianças são estereotipadas conforme o gênero em papéis determinados, inclusive nos tipos de brinquedos. Assim, o estereótipo social reforça que meninas sejam passivas e dependentes e, que os meninos mostrem-se como agressivos e independentes, sendo mais incentivados à prática de atividades motoras amplas e esportivas (CARDOSO; GAYA, 2004; PIEK et al., 2006; VALENTINI, 2007, 2002b). Esses estereótipos podem restringir a percepção que a menina tem de si mesma, sua motivação para desenvolver habilidades, e, consequentemente, sua competência real.

Dentre os diferentes, domínios diferenças entre os gêneros têm sido observadas quanto às percepções de competência atlética, conduta comportamental, aparência física e, autovalor global (BOIS et al., 2005; DALEY, 2002; HARTER, 1985; PIEK et al., 2006; RUDISILL et al.; 1993). Na competência atlética, geralmente os meninos apresentam percepções mais positivas quando comparados às meninas (CARROLL; LOUMIDIS, 2001; MAÏANO et al., 2004). Carroll e Loumidis (2001) e BOIS et al. (2005) atentam que a percepção mais elevada dos meninos pode ser decorrente da maior participação e competência dos meninos nas atividades físicas. Meninos participam mais em termos de tempo e em número de sessões semanais. Daley (2002), embora reforce essa perspectiva, sugere ainda que a diferença entre meninos e meninas esteja também relacionada aos seus diferentes motivos para a prática de exercícios. A participação feminina tende a ser motivada pela busca da diversão, o sentir-se bem e a busca e a manutenção de amizades enquanto que meninos buscam efetivamente competir e tornarem-se competentes. Além disso, tradicionalmente meninos recebem mais suporte de familiares adultos para o envolvimento em esportes (HARTER, 1985, 1992).

Movimento, Porto Alegre, v. 15, n. 01, p. 71-97, janeiro/março de 2009. 
Quanto às percepções em relação à aparência física, as diferenças de gênero podem estar associadas às mudanças psicológicas típicas que ocorrem com as meninas na época da adolescência (DALEY, 2002). A aparência física pode ter um papel mais significativo para as meninas do que para os meninos (DALEY, 2002; PIEK et al., 2006). Segundo esses pesquisadores, para as meninas, ter uma boa aparência ou ser bonita mostra-se como um valor mais importante, enquanto que, para os meninos, demonstrar habilidades tende a ser considerado o mais importante. Piek et al. (2006) afirmam ainda que devido à grande necessidade de conformar-se aos padrões do grupo na adolescência, questões referentes à forma de vestir-se e a aparência pessoal teriam um impacto maior no autovalor global e na percepção de maior aceitação da conduta comportamental das meninas.

O sentimento de competência ocasiona impacto na motivação intrínseca e no julgamento autônomo da criança. A criança que se percebe competente é mais intrinsecamente motivada para empenhar tarefas que a desafiem e para atingir metas autorreferenciadas; enquanto que aquela que se considera pouco competente tende a evitar situações desafiadoras e engaja-se em tarefas não necessariamente com metas próprias a serem conquistadas (DECI, 1998; HARTER; CONNEL, 1984). Muitas vezes as metas que levam crianças a engajarem-se em diferentes atividades são de adultos que convivem com a criança e de seus pares. Este controle externo no engajamento da tarefa, quando excessivo, diminui a motivação intrínseca e o engajamento nas atividades; repercutindo negativamente no desempenho de qualquer atividade que necessite criatividade, compreensão conceitual ou resolução flexível de problemas (DECI, 1998; HARTER, 1985; VALENTINI, 2007, 2002a; WHITE, 1959).

Além disso, a criança que exibe pouca motivação intrínseca talvez esteja menos consciente de sua competência por possuir poucas experiências prévias e, no decorrer das experiências, receberem pouco suporte de pessoas significativas (VALENTINI, 2007, 2002b). A necessidade de sentir-se competente é característica de um comportamento intrinsecamente motivado; portanto, a motivação deve ser entendida como resultado de experiências significativas em contextos que promovem de níveis de autoconfiança mais elevados

$M$ ovimento, Porto Alegre, v. 15, n. 01, p. 71-97, janeiro/março de 2009. 
(VALENTINI, 2006). Quando oportunidades de vivenciar desafios otimizados são oferecidas, a criança fortalece sua competência percebida e, consequentemente, torna-se mais competente e motivada ao manter-se na tarefa (DALEY, 2002 NEVES; BORUCHOVITCH, 2004; VALENTINI, 2007).

\section{Os AGENTES SOCIALIZADORES E O CONTEXTO DA CRIANÇA}

A história pregressa de socialização da criança conduz a mesma a interessar-se e interagir em diferentes tarefas, aceitando novos desafios e motivando-se para a conquista de novas habilidades. $\mathrm{O}$ ambiente de aprendizagem, e o modo como o professor realiza e apresenta as atividades são apontadas como fatores determinantes no desenvolvimento das percepções de competência (CARDOSO; GAYA, 2004; CARROL; LOUMIDIS, 2001; DALEY, 2002; FONSECA, 2004; GALLAHUE, 2001; KLINT; WEISS, 1987; NEVES; BORUCHOVITCH, 2004; VALENTINI, 2002a, 2002b; VALENTINI; TOIGO, 2004; VIEIRA et al., 1997; WEISS, 2004). Uma autoavaliação positiva é expressa por crianças e jovens quando experiências adequadas, oportunidade para a prática, instrução e encorajamento de pessoas significativas são propiciados (VALENTINI, 2007, 2002b).

Os procedimentos metodológicos utilizados pelo professor influenciam também como os estudantes se posicionam frente às demandas escolares. Quando o professor reconhece também as metas que as crianças estabelecem para a sua aprendizagem, este propõe questionamentos e desafios otimizados, evita a imposição de comparação social de desempenho, adapta a proposta metodológica às necessidades, interesses e características individuais dos alunos; criando um contexto que prioriza a eqüidade, a competência e o autoconceito positivo (FONSECA, 2004; VALENTINI, 2007; VALENTINI; TOIGO, 2004). Quanto mais a criança se integra positivamente ao ambiente escolar, mais ela valoriza as experiências neste ambiente e mais este ambiente se torna significativo para a mesma (VALENTINI, 2007).

Muitas vezes, mudanças na estrutura de referências da criança (séries, turmas, metodologias e professores) podem repercutir negativamente na forma como a criança se percebe. Observa-se também

Movimento, Porto Alegre, v. 15, n. 01, p. 71-97, janeiro/março de 2009. 
que conforme os estudantes avançam nas séries escolares, o ambiente escolar torna-se mais impessoal e avaliativo; a competição é ressaltada por meio da comparação de notas e conceitos, guiando crianças e adolescentes a orientarem-se na obtenção extrínseca de padrões pré-estabelecidos (HARTER, 1992).

Em qualquer ambiente de aprendizagem, as respostas dos agentes socializadores (pais, professores, técnicos, irmãos), relativas ao sucesso ou fracasso da criança na realização de uma atividade, têm impacto nas percepções de competência da mesma. O feedback advindo de pais, professores ou amigos servem como fonte de referências sobre a adequação do desempenho do indivíduo (HARTER 1978, 1992), tendo efeito positivo ou negativo no autoconceito dependente da importância e valor dado pela criança a esta experiência e a este indivíduo. Crianças e adolescentes interiorizam um sistema de metas por domínios que define a importância do sucesso numa determinada atividade. Neste experiência, a aprovação dos outros torna-se internamente representada, e transformada em parâmetro próprio de aprovação ou desaprovação (VIEIRA et al.,1997).

Portanto, considerando-se que as conquistas são influenciadas pelas percepções de competência do indivíduo e estas pelas características pessoais em resposta às experiências de sucesso no contexto de aprendizagem e a ação positiva dos agentes socializadores na vida da criança, o presente estudo tem como objetivos investigar: a) as percepções de competências de escolares; b) as diferenças quanto a séries, idades e gênero nas percepções de competência de escolares; c) a influência da reprovação escolar nas percepções de competência dos escolares; d) as relações entre os diferentes domínios de competência expressos por escolares. As seguintes hipóteses foram estabelecidas: a) escolares mais jovens ( 8 a 10 anos) de séries iniciais apresentariam níveis mais elevados de percepção de competência, nos diferentes domínios, quando comparados aos escolares mais velhos (11 a 12 anos e 13 a 14 anos) e de séries mais avançadas; b) meninos e meninas apresentariam diferenciação nos níveis de percepções de competência; c) escolares repetentes demonstrariam percepções de competência menos elevadas que alunos não repetentes; d) escolares com alta percepção de competência em um específico domínio apresentariam

Movimento, Porto Alegre, v. 15, n. 01, p. 71-97, janeiro/março de 2009. 
alta percepção de competência nos demais domínios; e) escolares com baixa percepção de competência em um específico domínio demonstrariam baixa percepção de competência em outros domínios.

\section{Metodologia}

\subsection{PARTICIPANTES}

Desta pesquisa descritiva, comparativa, transversal e correlacional (THOMAS; NELSON, 2002) participaram 96 crianças (49 meninos e 47 meninas) provenientes de escolas públicas com idades entre 8 a 14 anos. A amostra foi intencional e a distribuição das idades e dos gêneros ocorreu de acordo com a configuração apresentada pelas turmas das escolas pesquisadas. Para comparações nas idades, três grupos de faixas etárias distintas foram constituídos para o presente estudo (de 8 à 10 anos / de 11 e 12 anos/ de 13 e 14 anos). Esta pesquisa foi aprovada pelo comitê de ética da Universidade Federal do Rio Grande do Sul (UFRGS), processo no. 2003109 e somente participaram crianças cujos pais retornaram o termo de consentimento informado assinado.

\subsection{INSTRUMENTO}

Para avaliar a percepção de competência foi utilizada The SelfPerception Profile for Children (HARTER, 1985), validada para utilização com crianças brasileiras por Villwock (2006). A escala é composta por seis sub-escalas independentes, determinando cinco domínios específicos, bem como o autovalor global: (1) Competência Escolar (cognitiva); (2) Aceitação Pessoal (sócio-afetiva); (3) Competência Atlética (habilidades motoras); (4) Aparência Física (grau de satisfação com a aparência); (5) Conduta Comportamental (como age); (6) Auto Valor Global (a extensão na qual a criança gosta de si mesma). Cada uma das seis subescalas é composta por seis itens, constituindo um total de 36 questões. O escore de cada item na escala pode variar de 1 a 4 . Onde o valor "1" indica uma baixa percepção de competência, e o valor " 4 " demonstra uma alta percepção de competência.

Movimento, Porto Alegre, v. 15, n. 01, p. 71-97, janeiro/março de 2009. 


\subsection{Procedimentos}

Com a finalidade de expor os procedimentos para a administração do questionário, foi feito um contato prévio com as escolas por meio de carta de apresentação e entrevistas com seus diretores. Após o aceite dos pais ou responsáveis legais pelas crianças, o pesquisador iniciou a coleta de dados. O questionário foi conduzido de forma individual pelo pesquisador. Primeiramente, uma questão de exemplo foi conduzida, onde as crianças foram solicitadas a decidir com qual das duas crianças descritas no modelo elas mais se identificaram, ou seja, aquela opção que melhor assemelha-se a elas próprias, para então marcar a descrição escolhida. $\mathrm{O}$ valor numérico correspondente à escolha de cada criança foi registrado na folha de escore para respostas individuais da escala de percepção de competência.

\section{ANÁLISE DOS DADOS}

No presente estudo, a categorização da competência percebida em alta, moderada e baixa foi baseada no estudo de Harter et al. (1992): utilizando-se das médias e desvios padrões; para percepção de competência alta (acima da $\mathrm{M}+1 \mathrm{DP}$ ); percepção de competência moderada (M - 1 DP e M + 1 DP); e, percepção de competência baixa (abaixo da M - 1 DP). Para comparações nas diferentes idades e séries foram utilizadas análises de variâncias (ANOVA) e Tukey post hoc testes. Para comparar os gêneros, testes-t independentes. O nível de significância igual ou menor de $\mathrm{p}=0,05$ foi adotado. $\mathrm{O}$ Tes90p9te de Normalidade Kolmogorov-Smirnov evidenciou que a amostra encontrava-se normalmente distribuída ( $\mathrm{p}>0,05)$ possibilitando a aplicação de testes paramétricos (THOMAS; NELSON, 2002).

\section{Resultados}

Os participantes, em geral, apresentaram níveis moderados de percepção de competência escolar, aceitação social, competência atlética, aparência física, conduta comportamental e autovalor global. O autovalor global foi o único domínio que se aproximou de um

Movimento, Porto Alegre, v. 15, n. 01, p. 71-97, janeiro/março de 2009. 
elevado nível de percepção (ver Tabela 1 para médias nas subescalas da percepção de competência para total da amostra, gênero, idade, séries e condição ou não de aprovação).

Tabela 1. Médias de Competência Percebida nas diferentes Subescalas e Variáveis

\begin{tabular}{|l|l|l|l|l|l|l|}
\hline & & & & & & \\
\hline & & & & & & \\
\hline & & & & & & \\
\hline & & & & & & \\
\hline & & & & & & \\
\hline & & & & & & \\
\hline & & & & & & \\
\hline & & & & & & \\
\hline & & & & & & \\
\hline & & & & & & \\
\hline & & & & & & \\
\hline & & & & & & \\
\hline & & & & & & \\
\hline & & & & & & \\
\hline & & & & & & \\
\hline
\end{tabular}

\subsection{COMPARAÇÕES DAS PERCEPÇÕES DE COMPETÊNCIA NAS IDADES}

Diferenças significativas foram observadas nas percepções de competência escolar $(\mathrm{F}(2,93)=6,49 ; \mathrm{p}=0,002)$, aparência física $(\mathrm{F}(2,93)=3,85 ; \mathrm{p}=0,02)$, conduta comportamental, $(\mathrm{F}(2,93)=9,77 ; \mathrm{p}=0,000)$ e, autovalor global $(\mathrm{F}(2,93)=4,83 ; \mathrm{p}=0,01)$ nos diferentes grupos de idades. Resultados não significativos foram observados para aceitação social $(\mathrm{F}(2,93)=2,14 ; \mathrm{p}=0,12)$ e competência atlética $(\mathrm{F}(2,93)=0,07$; $\mathrm{p}=0,92)$.

Tukey post hoc testes indicam que, para a competência escolar, foram observadas diferenças significativas nas percepções das

Movimento, Porto Alegre, v. 15, n. 01, p. 71-97, janeiro/março de 2009. 
crianças entre 8 e 10 anos e adolescentes de 13 a 14 anos $(\mathrm{p}=0,002)$. As crianças da faixa etária de 8 a 10 anos $(\mathrm{M}=2,97, \mathrm{DP}=0,49)$ demonstraram índices mais elevados de percepção de competência escolar quando comparadas aos alunos de 13 a 14 anos $(\mathrm{M}=2,16, \mathrm{DP}=0,64)$. Ainda neste mesmo domínio, as crianças de 11 e 12 anos $(\mathrm{M}=2,70$, $\mathrm{DP}=0,63$ ) também apresentaram índices mais elevados quando comparadas aos adolescentes de 13 e 14 anos $(\mathrm{M}=2,16, \mathrm{DP}=0,64)$. $\mathrm{O}$ segundo domínio que apresentou diferenças significativas $(\mathrm{p}=0,02)$ foi a aparência física, novamente as crianças entre 8 e 10 anos $(\mathrm{M}=3,31, \mathrm{DP}=0,59)$ apresentaram índices mais elevados quando comparadas às crianças mais velhas, de 11 e 12 anos $(\mathrm{M}=2,93, \mathrm{DP}=0,81)$ e de jovens de 13 e 14 anos ( $M=2,64, \mathrm{DP}=0,78)$. Os níveis de competência percebida apresentados pelas crianças mais jovens, 8 a 10 anos $(\mathrm{M}=3,17, \mathrm{DP}=0,62)$, na variável conduta comportamental $(\mathrm{p}=0,000)$ também se mostraram mais elevados quando comparados aos níveis apresentados pelos dois grupos etários, 11 e 12 anos $(\mathrm{M}=2,66$, $\mathrm{DP}=0,74)$ e 13 e 14 anos $(\mathrm{M}=2,16, \mathrm{DP}=0,28)$. Diferenças significativas $(\mathrm{p}=0,01)$ também foram encontradas para o autovalor global. Nesse domínio, as crianças com idades entre 8 a 10 anos apresentam índices mais elevados $(\mathrm{M}=3,48, \mathrm{DP}=0,46)$ quando comparadas aos jovens de 13 e $14 \operatorname{anos}(\mathrm{M}=3,12, \mathrm{DP}=0,65)$. Esses resultados dão suporte à hipótese do presente estudo que esperava encontrar níveis mais elevados de percepção de competência em crianças mais jovens.

\subsection{COMPARAÇÕES DAS PERCEPÇÕES DE COMPETÊNCIA NAS SÉRIES}

Diferenças significativas foram observadas entre as crianças de diferentes séries quanto as percepções de aceitação social $(\mathrm{F}(2,93)=3,29 ; \mathrm{p}=0,04)$, conduta comportamental $(\mathrm{F}(2,93)=7,58$; $\mathrm{p}=0,001)$, e autovalor global, $(\mathrm{F}(2,93)=3,25 ; \mathrm{p}=0,04)$. Não foram encontrados resultados significativos para competência escolar $(\mathrm{F}(2,93)=2,12 ; \mathrm{p}=0,12)$, competência atlética $(\mathrm{F}(2,93)=2,18 ; \mathrm{p}=0,11)$ e aparência física $(F=(2,93)=2,44 ; p=0,09)$. Uma tendência à significância foi observada com relação à aparência física $(\mathrm{p}=0,09)$. Uma vez que a ANOVA foi significante para a aceitação social, conduta comportamental e autovalor global testes de continuidade foram realizados.

Movimento, Porto Alegre, v. 15, n. 01, p. 71-97, janeiro/março de 2009. 
Tukey post hoc testes indicam que para a aceitação social diferenças significativas foram observadas nas percepções de competência das crianças da terceira e quarta $(\mathrm{p}=0,05)$ e terceira e quinta $(\mathrm{p}=0,04)$ séries. Crianças da terceira série $(\mathrm{M}=3,22, \mathrm{DP}=0,56)$ demonstraram índices mais elevados de aceitação social quando comparadas às crianças da quarta $(\mathrm{M}=2,81, \mathrm{DP}=0,56)$ e quinta séries $(\mathrm{M}=2,82, \mathrm{DP}=0,65)$. Com relação à conduta comportamental, diferenças significativas foram observadas entre a terceira e quinta séries $(\mathrm{p}=0,05)$. Crianças da terceira série $(\mathrm{M}=2,95, \mathrm{DP}=0,62)$ apresentaram níveis mais elevados de conduta comportamental quando comparadas às crianças da quinta série $(\mathrm{M}=2,51, \mathrm{DP}=0,69)$. Com relação ao autovalor global, as diferenças significativas foram observadas entre a terceira e quinta séries $(\mathrm{p}=0,05)$. Crianças da terceira série $(\mathrm{M}=3,45, \mathrm{DP}=0,46)$ evidenciam percepções de autovalor global mais elevadas que crianças da quinta série $(\mathrm{M}=3,05, \mathrm{DP}=0,67)$. Esses resultados confirmam a hipótese estabelecida de que crianças nas séries mais adiantadas apresentariam níveis mais baixos de percepção de competência.

\subsection{COMPARAÇÕES DAS PERCEPÇÕES DE COMPETÊNCIA NO GÊNERO}

Teste-t independente foi utilizado para investigar possíveis diferenças nas percepções de competência com relação ao gênero. Os resultados estatísticos não evidenciam diferenças significativas entre os gêneros nas diferentes subescalas da percepção de competência. Meninos e meninas percebem-se semelhantes quanto à competência escolar $(\mathrm{t}(94)=0,09, \mathrm{p}=0,92)$, aceitação social $(\mathrm{t}(94)=0,19, \mathrm{p}=0,84)$, competência atlética $(\mathrm{t}(94)=0,65, \mathrm{p}=0,51)$, aparência física $(\mathrm{t}(94)=1,07$, $\mathrm{p}=0,28) \mathrm{e}$, autovalor global $(\mathrm{t}(94)=0,39, \mathrm{p}=0,69)$. Somente para conduta comportamental uma tendência à significância é observada nos resultados, $(\mathrm{t}(94)=1,76, \mathrm{p}=0,08)$. Observa-se que meninas tendem a perceber-se com conduta comportamental mais adequada socialmente $(\mathrm{M}=2,93, \mathrm{DP}=0,71)$ do que meninos $(\mathrm{M}=2,67, \mathrm{DP}=0,74)$, embora este resultado não seja significativo. Os resultados quanto ao gênero não dão suporte à hipótese estabelecida no presente estudo, a qual de forma geral esperava encontrar diferenças entre meninos e meninas na percepção de competência.

Movimento, Porto Alegre, v. 15, n. 01, p. 71-97, janeiro/março de 2009. 


\subsection{COMPARAÇõES DAS PERCEPÇÕES DE COMPETÊNCIA COM RELAÇÃO A GRUPOS REPETENTES E NÃO REPETENTES}

Para investigar a possibilidade de diferenças nas percepções de competência entre os alunos repetentes e os não repetentes, $o$ teste-t independente foi utilizado. Os resultados da análise estatística evidenciam diferença significativa somente no domínio da competência esco$\operatorname{lar}(\mathrm{t}(94)=2,59, \mathrm{p}=0,01)$, de forma que os alunos repetentes $(\mathrm{M}=2,55$, $\mathrm{DP}=0,71)$ tendem a perceber sua competência escolar em um nível mais baixo quando comparados aos alunos não repetentes $(\mathrm{M}=2,88$, $\mathrm{DP}=0,53)$. Os alunos repetentes não apresentaram diferenças significativas quando comparados aos alunos não repetentes nas variáveis: aceitação social $(\mathrm{t}(94)=0,36, \mathrm{p}=0,71)$, competência atlética $(\mathrm{t}(94)=1,02$, $\mathrm{p}=0,30)$, aparência física $(\mathrm{t}(94)=0,39, \mathrm{p}=0,69)$, conduta comportamental $(\mathrm{t}(94)=1,18, \mathrm{p}=0,24)$ e autovalor global $(\mathrm{t}(94)=0,07, \mathrm{p}=0,93)$.

\subsection{RELAÇÕES ENTRE PERCEPÇÕES DE COMPETÊNCIA ESCOLAR E DEMAIS} DOMÍNIOS DA PERCEPÇÃO DE COMPETÊNCIA

Uma vez que a percepção de competência escolar foi, nas comparações de grupos, o domínio da percepção de competência que se mostrou mais diferenciado, correlações entre este e os demais domínios foram realizadas utilizando-se a correlação de Pearson no geral da amostra e nos diferentes grupos de idade. Para todas as crianças da amostra, correlações significantes foram evidenciadas entre a competência escolar e aparência física, $r=0,19, p=0,03$ (positiva e fraca); competência escolar e conduta comportamental, $r=0,47$, $\mathrm{p}=0,000$ (positiva e moderada); e competência escolar e o autovalor global, $r=0,23, p=0,01$ (positiva e fraca). Uma tendência à significância foi observada entre a competência escolar e a competência atlética, $\mathrm{r}=0,14, \mathrm{p}=0,07$ (positiva e fraca), e uma correlação não significante entre a competência escolar e a aceitação social, $r=0,02, p=0,39$ (correlação negativa e fraca).

Nos diferentes grupos de idades, correlações foram encontradas para: (1) o grupo de idade 8 a 10 anos, entre a competência escolar e a conduta comportamental, $\mathrm{r}=0,43, \mathrm{p}=0,006$ (positiva e moderada); entre a competência escolar e a competência atlética, $r=0,29$, $p=0,01$

Movimento, Porto Alegre, v. 15, n. 01, p. 71-97, janeiro/março de 2009. 
(positiva e fraca); entre a competência escolar e a aparência física, $\mathrm{r}=0,25, \mathrm{p}=0,03$ (positiva e fraca); entre competência escolar e conduta comportamental, $\mathrm{r}=0,39, \mathrm{p}=0,001$ (positiva e moderada); (2) o grupo de idade entre 11 e 12 anos entre a competência escolar e o autovalor global, $r=0,19, p=0,08$, uma correlação significante (positiva e fraca); (3) e, finalmente, o grupo de idade 13 e 14 anos não apresentou nenhuma correlação significante entre a competência escolar e os demais domínios da percepção de competência. As demais correlações nos grupos de idades não foram significativas.

\subsection{DISCUSSÃO DOS RESULTADOS}

As crianças da amostra do presente estudo apresentaram níveis moderados de percepção nos domínios competência escolar, aceitação social, competência atlética, aparência física, conduta comportamental e autovalor global. Os níveis de percepção de competência desse estudo assemelham-se aos resultados apresentados por outros estudos realizados (CHEN et al., 2004; VALENTINI, 2002b; VILLWOCK, 2006) porém, diferenciam-se do estudo de Vieira et al. (1997). No estudo de Vieira et al. (1997), os pesquisadores encontraram valores mais baixos de competência escolar, aceitação social e competência atlética quando comparado ao presente estudo. Os níveis moderados de competência percebida do presente estudo alinham-se com os resultados de Villwock (2006) em crianças (entre 8 e 10 anos) da rede pública do município de São Leopoldo (RS); com os resultados de Valentini (2002b) com crianças entre 5 a 10 anos nas escolas públicas de Porto Alegre; e, com os resultados de Chen et al. (2004) com crianças de $5^{\mathrm{a}}$ e $6^{\mathrm{a}}$ séries do ensino fundamental.

Nos resultados do presente estudo foi observado o platô nas percepções, a partir dos 8 anos de idade, descrito por diversos pesquisadores (HARTER, 1985; RUDISILL et al., 1993; Ulrich, 1987). A estabilização da competência percebida tem sido observada em crianças entre 9 e 11 anos de idade, no presente estudo o platô se evidencia fortemente a partir dos 11 anos. Este platô indica que gradualmente a criança adquire a habilidade cognitiva para considerar e avaliar os diversos fatores que influenciam seus desempenhos, como por exemplo, o feedback de pessoas significativas; as experiências passadas; as

Movimento, Porto Alegre, v. 15, n. 01, p. 71-97, janeiro/março de 2009. 
conquistas ou fracassos nas mesmas; os tipos de tarefas; e a interação pessoal no processo. A estabilização das percepções ocorre paralela, em geral, ao aumento da competência real da criança, guiando a criança a tornar-se mais precisa quanto aos próprios julgamentos e avaliações, permanecendo num grau moderado de percepção de competência, fato este observado no presente estudo. Crianças e adolescentes que conhecem suas capacidades e dificuldades são mais propensas a regular adequadamente o seu comportamento (CHEN et al., 2004); a conscientização das reais capacidades e habilidades de um indivíduo éimportante para a realização de uma auto-avaliação adequada e no estabelecimento de estratégias de conquista (VALENTINI, 2002b).

Nesse mesmo período de transição, ocorre uma diminuição da influência da família, e o grupo de amigos ganha mais força e importância, do mesmo modo que professores e outros adultos lentamente perdem o poder de persuasão sobre a criança e a influência na competência percebida pelos mesmos. Este período do desenvolvimento tem sido, portanto, considerado fundamental para o fortalecimento das percepções de competência, pois nesse período a criança apresenta uma conscientização das potencialidades e capacidades individuais estabelecendo parâmetros para o seu desempenho futuro (VALENTINI, 2002b).

\subsection{PERCEPÇÕES DE COMPETÊNCIA NAS IDADES}

As comparações das percepções de competência nas idades evidenciaram diferenças significativas, especificamente nas subescalas competência escolar, aparência física, conduta comportamental e autovalor global. Os dados indicam que as crianças de 8 a 10 anos evidenciam níveis mais elevados de percepção de competência, e conforme as idades aumentam, principalmente no grupo de idade de 13 a 14 anos, os níveis mantêm-se moderados, mas apresentando escores mais baixos.

Os níveis mais elevados de percepção de competência das crianças mais jovens do presente estudo sugerem a falta de precisão para julgar suas competências, o qual é muitas vezes decorrente da falta de critérios e parâmetros auto avaliativos (VALENTINI, 2002b).

Movimento, Porto Alegre, v. 15, n. 01, p. 71-97, janeiro/março de 2009. 
Harter e Connel (1984) afirmam que crianças mais jovens possuem poucas experiências para realizarem julgamentos autônomos, assim, necessitam mais do feedback de um adulto como uma fonte de avaliação de suas habilidades (CARROLL; LOUMIDIS, 2001). É somente a partir do aumento das experiências no meio social, que crianças passam a acessar sua própria competência na comparação do seu desempenho com o de seus pares (PIEK et al., 2006). Com a comparação social as crianças se tornam, progressivamente, capazes de sintetizar a informação recebida de modo mais preciso, surgindo desse processo, um julgamento mais realista das suas reais capacidades e competências (HARTER, 1985, 1987); e, embora as comparações ocorram as mesmas não são garantia de que crianças de séries iniciais demonstrem precisão ao identificar seus níveis de competência (ULRICH, 1987).

\subsection{PeRCEPÇÕES DE COMPETÊNCIA NAS SÉRIES ESCOLARES}

As comparações nas séries evidenciaram diferenças significativas nas percepções de aceitação social; conduta comportamental; e, autovalor global. Os alunos da terceiras séries, quando comparados aos alunos das demais séries, demonstraram níveis mais elevados de percepções de competência. Observa-se que, conforme as crianças progridem nas séries escolares, elas passam a adaptarem-se às demandas da cultura escolar, a qual reforça uma orientação extrínseca (HARTER, 1992); a qual repercute de maneira efetiva nas percepções de competência, uma vez que as crianças têm seu valor pessoal muitas vezes associado as suas notas. Esta adaptação a parâmetros externos pode, possivelmente, gerar um desinteresse no processo de aprendizagem.

As diferenças apresentadas entre as séries, principalmente entre $3^{\mathrm{a}}$ e $5^{\mathrm{a}}$ séries parecem revelar a percepção das crianças de que, à medida em que avançam na escola, o ambiente de aprendizado tornase mais impessoal, mais formal e, principalmente, mais avaliador e competitivo (HARTER, 1992). Harter (1992) enumera uma série de fatores (competição escolar, importância em conhecer a resposta certa, percepções de controle do professor) que são apontadas pelos estudantes como comuns dentro das práticas educacionais, as quais repercutem negativamente na competência percebida quando a criança

Movimento, Porto Alegre, v. 15, n. 01, p. 71-97, janeiro/março de 2009. 
ou adolescente não cumpre esta expectativa. Chen et al. (2004) sugerem ainda que níveis moderados de percepção de competência cognitiva e social, em crianças de $5^{\mathrm{a}}$ e $6^{\mathrm{a}}$ séries, podem refletir as dificuldades da criança frente a uma etapa diferenciada do ensino, e frente às mudanças maturacionais que estão ocorrendo neste período.

\subsection{NívEIS DE PERCEPÇÃO DE COMPETÊNCIA NOS GÊNEROS}

Comparações foram realizadas entre os níveis de percepções de competências dos gêneros. Os resultados das análises estatísticas não evidenciaram diferenças significativas entre meninos e meninas nas diferentes subescalas da percepção de competência. O único domínio a apresentar uma tendência à diferença significativa foi a conduta comportamental. Aqui, observa-se que meninas tendem a perceber-se com conduta comportamental social mais adequada que a dos meninos. Dessa forma, as meninas do presente estudo demonstraram uma tendência a aceitar mais o modo como se comportam, bem como, se percebem mais determinadas a agirem de forma a evitar envolvimento em problemas (HARTER, 1985).

Os resultados do presente estudo estão de acordo com outras pesquisas realizadas com crianças brasileiras (VALENTINI, 2002a, 2002b; VIEIRA et al., 1997). Valentini (2002b) sugere que quando são oferecidas oportunidades para o desenvolvimento adequado das capacidades, meninos e meninas apresentarão percepções de competência similares. As semelhanças observadas no presente estudo entre meninos e meninas podem indicar um envolvimento semelhante de meninos e meninas nas diferentes atividades, bem como oportunidades de interação e expectativas equivalentes do contexto social que as rodeiam. Entretanto, mais pesquisas são necessárias investigando o contex to familiar e social, para precisamente inferir quais os fatores que mais fortemente estão associados com essas semelhanças.

5.10 Nível DA PERCEPÇÃO DE COMPETÊNCIA ENTRE ALUNOS REPETENTES E NÃO REPETENTES

As comparações realizadas entre as percepções de competência entre os grupos repetentes e não repetentes evidenciaram diferença

Movimento, Porto Alegre, v. 15, n. 01, p. 71-97, janeiro/março de 2009. 
significativa somente no domínio da competência escolar. Alunos repetentes percebem-se menos competentes cognitivamente quando comparados aos seus pares não repetentes. As percepções de competência, para um determinado domínio, podem ser consideradas como o resultado de uma história de conquistas e fracassos (HARTER, 1978), no presente estudo, os níveis mais baixos de percepção de competência escolar fortalecem esta perspectiva, uma vez que a repetência é entendida pessoalmente e socialmente como um fracasso pela criança, pelo adolescente e por seus familiares.

O contexto social corrobora fortemente com este entendimento usando muitas vezes a possibilidade de repetência como forma de pressão e exclusão social. A forma como a criança percebe o ambiente escolar e sua organização social (HARTER, 1984, 1992) é decisiva na construção de percepções positivas. Se a criança perceber esse ambiente como ameaçador e vivencia fracassos sucessivos, essa criança estará mais propensa a perceber-se menos competente, deixando de realizar tarefas e engajar-se nas atividades; o não engajamento nas atividades escolares repercute fortemente na competência atual dessa criança. Observa-se nas crianças e adolescentes investigados uma descrença em suas habilidades escolares que envolvem a cognição. Percepções de competência em níveis baixos está associada ao não aceitar desafios, a diminuição progressiva da curiosidade $e$ com o enfraquecimento da aprendizagem independente (HARTER, 1992), todos esses fatores são decisivos na construção, por parte da criança, na autoconfiança em sua capacidade de aprender (VALENTINI, 2002b). Ao perceber-se pouco competente e ao não confiarem em suas habilidades, a criança e o adolescente enfrentam experiências novas com insegurança ou medo (GALLAHUE, 2001) e dificilmente tentarão experimentar novas tarefas com autonomia (RUDISILL et al., 1993), fragilizando o autoconceito deste indivíduo. É necessário, portanto, considerar a influência das experiências bem-sucedidas, e também atentar para os efeitos daquelas situações onde ocorre fracasso (HARTER, 1978). Se estas crianças e adolescentes repetentes continuarem a vivenciar fracassos, a percepção da falta de competência escolar pode ser fortalecida repercutindo provavelmente no abandono escolar.

Movimento, Porto Alegre, v. 15, n. 01, p. 71-97, janeiro/março de 2009. 
No contexto investigado, as percepções de competência dos repetentes dos demais domínios, bem como o autovalor global, não pareceram estar sofrendo a influência negativa das percepções de competência escolar. Embora a princípio este dado possa parecer positivo, devemos considerar que, conforme observa Harter (1999), a falta de sucesso em domínios considerados não importantes pelo indivíduo não irá prejudicar o autovalor global e a auto-estima da criança. Em outras palavras, o que preocupa é se as crianças e adolescentes repetentes valorizam de fato o conhecimento escolar. Essa evidência pode refletir a falta de importância da escola na percepção dos alunos repetentes, sugerindo que o papel da escola em suas vidas não ocupa o mesmo espaço que outros domínios, como a vida social, pois nas relações sociais os mesmos perceberam-se efetivamente competentes.

Para crianças e adolescentes que se percebem pouco competentes, é necessário que a escola e a família promovam oportunidades de prática e instrução adequadas, e encorajamento (VIEIRA, 1993). Por meio de um planejamento adequado, o qual possibilite para crianças e jovens experiências enriquecedoras, otimizando as suas capacidades, as experiências de aprendizagem das crianças repetentes podem ser enriquecidas. Para a escola cabe a responsabilidade de reavivar o interesse dessas crianças no contexto escolar por meio de, entre outras estratégias, abordagens que promovam a motivação e que integrem a família e o aluno. Quando estratégias de motivação são utilizadas objetivando a conquista e domínio de uma habilidade, especialmente para crianças que demonstram pouco rendimento escolar, um processo de autovalorização é reforçado (VALENTINI, 2002a). Ainda o valor da criança e do adolescente não pode ser diminuído se o desempenho acadêmico dos mesmos não satisfizer as expectativas dos adultos (GALLAHUE, 2001). No que refere à família, alunos sem repetência relatam a existência de um maior suporte familiar no momento das tarefas escolares (PEIXOTO, 2004). Portanto, o resgate do suporte familiar para as atividades escolares dos repetentes torna-se, no grupo investigado, essencial. As famílias das crianças repetentes precisam ser alertadas quanto à falta de importância que a escola assumiu na vida dessas crianças e adolescentes e, juntos,

Movimento, Porto Alegre, v. 15, n. 01, p. 71-97, janeiro/março de 2009. 
escola, crianças e adolescentes e suas famílias, devem procurar meios de evitar que novos fracassos ocorram.

Outro fator a ser considerado é quanto a organização do sistema educacional não está abrandando o interesse intrínseco da aprendizagem (DECI, 1998). Considerando a influência desses fatores em futuras pesquisas, o ambiente escolar em que estão inseridos os repetentes deveria ser mais fortemente investigado. Ou seja, quais os fatores responsáveis pelos níveis de competência expressos pelos repetentes no domínio cognitivo. Conforme sugere Deci (1998) diversas oportunidades podem resultar em diferentes sentimentos e percepções na sua experiência.

\subsection{PERCEPÇÃO DE COMPETÊNCIA: RELAÇÕES ENTRE OS DIFERENTES DOMÍNIOS}

Nas relações estabelecidas entre a competência escolar e os demais domínios foram evidenciadas correlações significativas para todas as crianças da amostra. Os grupos de crianças mais jovens ( 8 a 10 e 11 a 12 anos) estão preocupados com o modo como suas atitudes estão de acordo com os valores e padrões estabelecidos dentro do ambiente escolar. É necessário compreender que, para estas crianças, o ambiente escolar é um espaço de novas significações sociais, onde embora a família permaneça importante, outros adultos significativos, como os professores, passam a ter um impacto no desenvolvimento das mesmas. Mesmo tratando-se de crianças já inseridas, há no mínimo três anos na escola, a organização social das mesmas tem no professor o centro de referência (GALLAHUE, 2001), assim, a valorização do desempenho escolar e sua repercussão no âmbito social são percebidas pela criança, a qual procura adequar sua conduta às regras estabelecidas pela escola e por adultos significativos.

Para o grupo de idade de 11 a 12 anos, as relações observadas entre as percepções de competência escolar e atlética sugerem que este grupo de escolares valoriza a atividade física. Por meio da participação em jogos as crianças procuram vivenciar novas formas de melhorar suas habilidades. As habilidades nos jogos e brincadeiras

$M$ ovimento, Porto Alegre, v. 15, n. 01, p. 71-97, janeiro/março de 2009. 
rotineiras da infância são valorizadas pelas crianças que fazem das mesmas um meio de aumentar a interação social e expandir os grupos de amizade (VALENTINI; TOIGO, 2004). É importante ressaltar que, para as crianças mais jovens, as informações advindas de pais e professores servem como referência para os comportamentos e adequação da performance do indivíduo (HARTER, 1978), fato observado nas relações estabelecidas nesta faixa etária.

Conforme as crianças se desenvolvem, e com isto aumentam suas interações sociais, os adultos perdem uma significativa parcela de sua influência sobre as mesmas, e o grupo de amigos adquire maior importância, de modo que os estudantes tendem a diferenciar suas percepções no ambiente escolar (HARTER, 1992). Essa expectativa é confirmada na ausência de relações significativas entre a competência escolar e as demais dimensões do comportamento no grupo de idade 13 a 14 anos. Esses resultados fortalecem o entendimento de que, conforme as crianças avançam pelas séries escolares e percebem o funcionamento do contexto escolar, elas tendem a diferenciar o desempenho escolar de sua vida particular e do relacionamento com os pares. Infelizmente, esses resultados também podem sugerir o crescente desinteresse do aluno com a escola, valorizando mais efetivamente outros domínios do comportamento, como a aceitação social pelos pares, a competência atlética nas atividades esportivas e a aparência física. Segundo Vieira (1993), para o adolescente ser aceito no grupo sua aparência deve estar em conformidade com os padrões da sociedade adolescente. Isso também inclui comportar-se de modo a parecer interessante aos pares e amigos. Nestes domínios, as crianças mais velhas, em geral, perceberam-se mais competentes. Toda essa preocupação sugere uma alteração na percepção dos valores em relação aos pais e à família. Na adolescência observa-se a formação de novas autopercepções, possivelmente marcadas principalmente, pelo aumento da importância dos pares (VIEIRA, 1993; VIEIRA et al., 1997), fato evidente no presente estudo.

Portanto, os critérios utilizados pelo indivíduo para determinar o quanto o sucesso ou fracasso no processo de aprendizagem tende a mudar com a idade (ULRICH, 1987); sendo que as crianças mais jovens demonstram precisar mais do feedback de um adulto como

$M$ ovimento, Porto Alegre, v. 15, n. 01, p. 71-97, janeiro/março de 2009. 
uma fonte de sua percepção de competência, adequando-se as normas escolares mais facilmente, e com o aumento da idade, a importância do grupo de amigos aumenta, e torna-se fator decisivo de influência (CARROLL; LOUMIDIS, 2001).

\section{CONSIDERAÇõES FINAIS}

Os resultados apresentados nessa pesquisa reforçam a necessidade de compreender como as crianças desenvolvem suas percepções e julgamentos sobre suas habilidades e aptidões. Essa compreensão, mais do que um recurso, apresenta-se como uma necessidade da escola e do professor de proporcionar um ambiente de ensino adequado a todos, do mais habilidoso ao inseguro e com dificuldades escolares, e que gere competência e autonomia.

Considerando as percepções das crianças investigadas e as poucas oportunidades de crianças provindas de famílias em desvantagem socioeconômicas, a escola deve configurar-se em um espaço de maior interação de seus estudantes, promovendo atividades extracurriculares. Crianças que participam de atividades extracurriculares no ambiente escolar tendem a apresentar níveis de percepções de competência mais elevados do que crianças e adolescentes que não participam de atividades extracurriculares (DALEY, 2002). Além disso, o esporte extracurricular pode ser uma estratégia efetiva da escola para influenciar positivamente as percepções de competência e o autoconceito de seus estudantes. Crianças e jovens que participam de programas esportivos organizados percebem-se mais competentes em decorrência de vivenciarem sentimentos de afiliação; perceberem-se competentes ao adquirirem novas habilidades; transporem novos desafios e ampliarem suas relações e interações sociais.

Destaca-se, ainda, a importância e a responsabilidade do professor de Educação Física compreender as dificuldades e necessidades das crianças e jovens durante o planejamento e execução das atividades físicas; desenvolver atividades desafiadoras e significativas; utilizar rotineiramente estratégias adequadas de encorajamento e feedback; promover a auto-superação evitando situações de humilhação ou de excessiva comparação. A implementação de um contexto

$M$ ovimento, Porto Alegre, v. 15, n. 01, p. 71-97, janeiro/março de 2009. 
de aprendizagem adequado ao desenvolvimento deve encorajar a criança e o jovem por meio da oferta de experiências diversas e oportunidades em níveis de desafio otimizados e gradativamente mais complexos, a desenvolverem a competência real e percebida na aula de Educação Física.

Para crianças e adolescentes que vivenciam fracassos, como a repetência escolar, estratégias conjuntas de ação de pessoas significativas (familiares, professores e pares) envolvidos no processo de educação dessas crianças devem reforçar a importância da escola na vida dos mesmos, promovendo experiências bem sucedidas e diversificadas nas quais os escolares possam iniciar o desenvolvimento qualificado de suas próprias habilidades, sejam elas atléticas, cognitivas ou sociais.

Perceptions of Competence: an Study With

Children And Adolescents From Elementary

School.

Abstract: The objective of this study was to investigate how children perceived their competence in the different domains of human behavior. The Perceived Competence Scale was used with 96 children from elementary public school. The results suggested that: a) older children showed lower levels of perceived competence; b) boys and girls perceived competence in the different domains were similar; c) cognitive perceptions of competence were lower in older children as well as in children that repeated school year; e, d) the lower perceptions of cognitive competence appears have no effect in the perceptions of competence in the others domains.

Keywords: Perception. Competency-based education. Children.

Movimento, Porto Alegre, v. 15, n. 01, p. 71-97, janeiro/março de 2009. 


\begin{abstract}
Percepciones de Competencia: un Estudio de Niños e Adolescentes de la Enseñanza Fundamental

Resumen: El objetivo de este estudio fue investigar cómo niños expresan sus percepciones de competencia en los diferentes dominios del comportamiento humano. Se ha utilizado la Escala de Percepción de Competencia para Niños con 96 niños de la enseñanza fundamental pública. Los resultados sugieren que a) niños mayores presentan niveles de percepción de competencia más bajos; b) las percepciones de competencia de niños y niñas en los diferentes dominios han sido semejantes; c) la percepción de competencia escolar es inferior para los niños mayores y repitentes; y d) la menor competencia escolar percibida parece no afectar los niveles de competencia en los demás dominios.

Palabras clave: Percepción. Educación basada en competencias. Niños.
\end{abstract}

\title{
REFERÊNCIAS
}

BOIS, Julien; SARRAZIN, Philippe G.; BRUSTAD, Robert J.; TROUILLOUD, David O.; CURY, François. Elementary school children's perceived competence and physical activity involvement: the influence of parents' role modeling behaviors and perceptions of their child's competence. Psychology of Sport and Exercise, New York, n. 6, p. 381-397, 2005.

CARDOSO, Marcelo; GAYA, Adroaldo. Os fatores motivacionais para a prática desportiva e suas relações com o sexo, idade e níveis de desempenho esportivo. Desporto para crianças e jovens: razões e finalidades. Porto Alegre: Editora da UFRGS, 2004, p. 289-313.

CARROLL, Bob; LOUMIDIS, Julia. Children's perceived competence and enjoyment in physical education and physical activity outside school. European Physical Education Review, Driffield, v. 7, p. 24-43, 2001.

CHEN, Xinyin; ZAPPULLA, Carla; COCO, Alida; SCHNEIDER, Barry; KASPAR, Violet; OLIVEIRA, Ana Maria; HE, Yunfeng; LI, Dan; LI, Boshu; BERGERON, Natasha; TSE, Hennis; SOUZA, Amanda. Self-perceptions in Brazilian, Canadian, Chinese and Italian children: Relations with social and school adjustment. International Journal of Behavioral Development, London, n. 28, v. 2, p. 129-138, 2004.

DALEY, Amanda. Extra-curricular physical activities and physical self-perceptions in British 14-15-year-old male and female adolescents. European Physical Education Review, Driffield, v. 8, p. 37-49, 2002.

Movimento, Porto Alegre, v. 15, n. 01, p. 71-97, janeiro/março de 2009. 
DECl, Edward. Porque fazemos o que fazemos: entendendo a auto motivação. São Paulo: Negócio Editora, 1998.

FONSECA, Antônio Marcos. O abandono das práticas desportivas: aspectos psicológicos. Desporto para crianças e jovens: razões e finalidades. Porto Alegre, Editora da UFRGS, p. 265-288, 2004.

GALLAHUE, David. Compreendendo o Desenvolvimento Motor: bebês, crianças, adolescentes e adultos. São Paulo: Phorte Editora, 2001.

GOODWAY, Jacqueline; RUDISILL, Mary Elizabeth. Influence of a Motor Skill Intervention Program on Perceived Competence of At-Risk African American Preschoolers. Adapted Physical Activity Quarterly, Champaign, n. 13, p. 288301, 1996.

HARTER, Susan. Effectance motivation reconsidered: toward a developmental model. Human Development, Berkeley, n. 1, p. 34-64, 1978.

HARTER, Susan. Manual for the self-perception profile for children. Colorado: University of Denver, 1985.

HARTER, Susan. The construction of the self: a developmental perspective. New York: Guilford Press, 1999.

HARTER, Susan. The relationship between perceived competence, affect, and motivational orientation within the classroom: Processes and patterns of chance. In: BOGGIANO, A. K.; PITTMAN, T.S. Achievement and Motivation: a socialdevelopmental perspective. Cambridge: University Press, 1992, p. 77-113.

HARTER, Susan; CONNEL, James. A model of children's achievement and related self-perceptions of competence, control, and motivational orientation. Advances in Motivation and Achievement, Stanford, v. 3, p. 219-250, 1984.

HARTER, Susan; WHITESELL, Nancy. KOWALSKI, Patricia; Individual Differences in the effects of Educational Transitions on Young Adolescent's Perceptions of Competence and Motivational Orientation. American Educational Research Journal, Washington, v. 29, n. 4, p. 777-807, 1992.

KLINT, Kimberly; WEISS, Maureen. Perceived Competence and Motives for Participating in Youth Sports: A Test of Harter's Competence Motivation Theory. Journal of Sport \& Exercise Psychology, Champaign, v. 9, p. 55-65, 1987.

MAÏANO, Christophe; NINOT, Grégory; BILARD, Jean. Age and gender effects on global self-esteem and physical self-perception in adolescents. European Physical Education Review, Driffield, v. 10, p. 53-69. 2004.

NEVES, Edna.; BORUCHOVITCH, Evely. A Motivação de Alunos no Contexto da Progressão Continuada. Psicologia: Teoria e Pesquisa, Brasília, v. 20, n.1, p. 7785, 2004.

PEIXOTO, Francisco. Qualidade das relações familiares, autoestima, autoconceito e rendimento acadêmico. Análise Psicológica, Lisboa, v. 1, p. 235-244, 2004.

Movimento, Porto Alegre, v. 15, n. 01, p. 71-97, janeiro/março de 2009. 
PIEK, Jan; BAYNAM, Grant; BARRET, Nicholas. The relationship between fine and gross motor ability, self-perceptions and self-worth in children and adolescents. Human Movement Science, Amsterdam, v. 25, p. 65-75. 2006.

RUDISILL, Mary Elizabeth; MAHAR, Matthew; MEANEY, Karen. The relationship between children's perceived and actual motor competence. Perceptual and Motor Skills, Missoula, v. 76, p. 895-906. 1993.

THOMAS, Jerry; NELSON, Jack. Métodos de pesquisa em atividade física. Porto Alegre, Artmed, 2002.

ULRICH, Beverly. Perceptions of Physical Competence, Motor Competence, and Participation in Organized Sport: Their Interrelations in Young Children. Research Quarterly for Exercise and Sport, Danvers, v. 58, p. 57-67. 1987.

ULRICH-FRANCE, Sarah; SMITH, Alan. Perceptions of relationships with parents and peers in youth sport: Independent and combined prediction of motivational outcomes. Psychology of Sport and Exercise, New York, v. 7, p. 193-214. 2006.

VALENTINI, Nadia Cristina. A influência de uma intervenção motora no desempenho motor e na percepção de competência de crianças com atrasos motores. Revista Paulista de Educação Física, São Paulo, v. 16, p. 61-75, 2002a.

Competência e autonomia: desafios para a Educação Física Escolar. Revista Brasileira de Educação Física do Esporte, São Paulo, v. 20, p. 185187. 2006.

Competência Percebida: Considerações para promover a aprendizagem. Em: KREBS, R.J.; FERREIRA NETO, C.A. Tópicos em desenvolvimento motor na infância e adolescência. Rio de Janeiro: Editora LECSU, p. 137-157, 2007.

Percepções de Competência e Desenvolvimento Motor de meninos e meninas: um estudo transversal. Movimento, Porto Alegre, v. 8, n. 2, p. 51-62. 2002b.

VALENTINI, Nadia Cristina; TOIGO, Adriana Marques. Ensinando Educação Física nas séries iniciais: Desafios \& Estratégias. Canoas: Editora Unilasalle/Salle, 2004.

VIEIRA, Lenamar. Relação entre a percepção de competência de atletas adolescentes e seus motivos para a prática esportiva. Revista da Educação Física da UEM, Maringá, v. 4, n. 1, p. 44-44, 1993.

VIEIRA, Lenamar; VIEIRA, José Luis; KREBS, Ruy Jornada. Análise da percepção de competência no contexto escolar. Kinesis, Santa Maria, v. 15, n. 1, p. 55-66, 1997.

VILLWOCK, Gabriela. O estudo desenvolvimentista da percepção de competência atlética, da orientação motivacional, da competência motora e suas relações em crianças de escolas públicas. Dissertação (Mestrado), Porto Alegre: Universidade Federal do Rio Grande do Sul, 2006.

Movimento, Porto Alegre, v. 15, n. 01, p. 71-97, janeiro/março de 2009. 
WEISS, Maureen. Developmental sport and exercise psychology: a lifespan perspective. Morgantown: Fitness Information Technology, 2004.

WHITE, Richard. Motivation Reconsidered: the concept of competence.

Psychological Review, Washington, v. 66, n. 5, p. 297-333, 1959.

Movimento, Porto Alegre, v. 15, n. 01, p. 71-97, janeiro/março de 2009. 